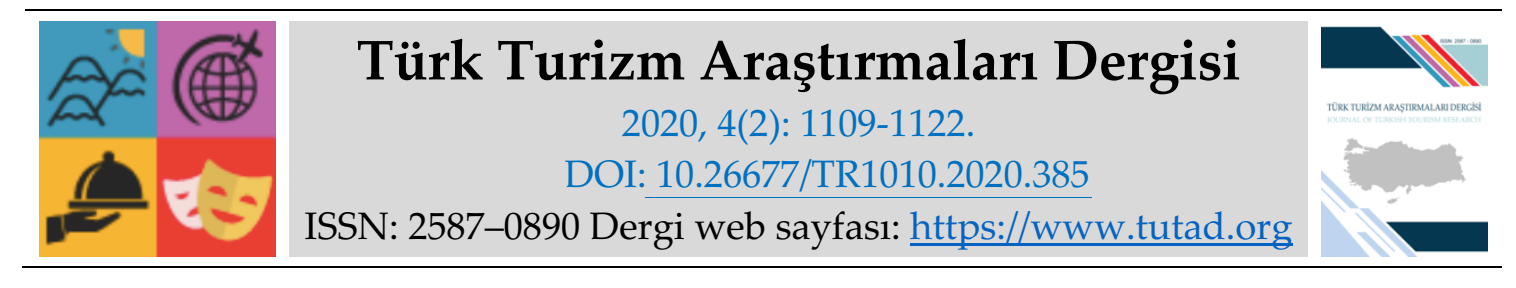

ARAŞTIRMA MAKALESI

\title{
Turizmde Beşeri Sermaye Gelişiminin Rolü: Turizme Bağımlı Ekonomiler İçin Panel Veri Analizi
}

Öğr. Gör. Dr. Erdal ALANCIOĞLU, Harran Üniversitesi, Bozova MYO, Şanlıurfa, e-posta: ealancioglu@harran.edu.tr

ORCID: https://orcid.org/0000-0002-5008-4957

Dr. Öğr. Üyesi Mustafa ŞiT, Harran Üniversitesi, Turizm ve Otel İşletmeciliği Yüksekokulu, Şanlıurfa, e-posta: msit@harran.edu.tr

ORCID: https://orcid.org/0000-0001-9694-0547

Öz

Bu çalışmada ekonomisi önemli ölçüde turizm gelirlerine bağlı olan ülkelerde 1995-2017 dönemi için beşeri sermaye ve turizm gelirleri ilişkisinin analiz edilmesi amaçlanmıştır. Bu amaç doğrultusunda Gengenbach, Urbain ve Westerlund (2016), eşbütünleşme testi ve DOLSMG tahmincisi ile panel veri analizi yapılmıştır. Çalışma; GSYİH içinde turizm gelirlerinin payı yüksek olan ülkeler özelinde ikinci nesil yeni ekonometrik modellerle testler yapıldığı ve ülke bazlı katsayı tahmin sonuçları elde edildiği için literatüre katkı sağlamaktadır. Çalışmanın bulgularına göre, beşeri sermaye ile turizm gelirleri arasında uzun dönemli bir ilişki tespit edilmiştir. Ayrıca katsayı tahminine göre, beşeri sermaye ve turizm gelirleri arasındaki ilişkinin pozitif ve istatistiki olarak anlamlı olduğu kanıtlanmıştır. Bu ülke grubunda beşeri sermaye artışı turizm gelirlerini olumlu etkilemektedir.

Anahtar Kelimeler: Turizm Gelirleri, Beşeri Sermaye, Panel Veri Analizi.

Makale Gönderme Tarihi: 14.01 .2020

Makale Kabul Tarihi: 05.04.2020

\section{Önerilen Atıf:}

Alancıŏlu, E. ve Şit, M. (2020). Turizmde Beşeri Sermaye Gelişiminin Rolü: Turizme Bağımlı Ekonomiler İçin Panel Veri Analizi, Türk Turizm Araştırmaları Dergisi, 4(2): 1109-1122.

(c) 2020 Türk Turizm Araştırmaları Dergisi. 


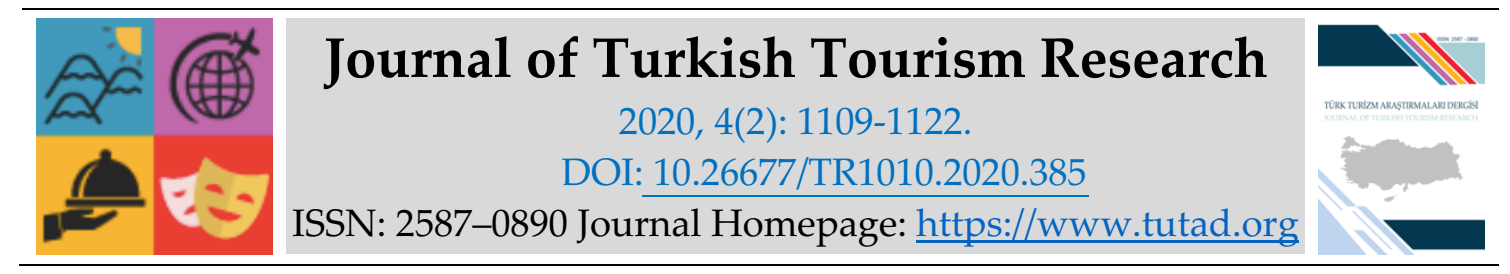

RESEARCH PAPER

\title{
The Role of Human Capital Development in Tourism: A Panel Data Analysis for Tourism-Dependent Economies
}

Dr. Erdal ALANCIOĞLU, Harran University, Bozova Vocational School, Şanlıurfa, e-mail: ealancioglu@harran.edu.tr ORCID: https://orcid.org/0000-0002-5008-4957

Assistant Prof. Dr Mustafa Şi̇T, Harran University, School of Tourism and Hotel Management, Şanlıurfa, e-mail: $\underline{\text { msit@harran.edu.tr }}$

ORCID: https://orcid.org/0000-0001-9694-0547.

\begin{abstract}
The aim of this study is to analyze the relationship between human capital and tourism receipts for the period of 1995-2017 in countries whose economy depends heavily on tourism receipts. For this purpose, panel data analysis was performed with Gengenbach, Urbain and Westerlund (2016) cointegration test and DOLSMG estimator. The study contributes to the literature, especially since the tests are made with the second-generation new econometric models and the country-based coefficient estimation results are obtained especially for the countries whose a high share of tourism receipts in GDP. According to the findings, a long-term relationship has been determined between human capital and tourism receipts. In addition, according to the coefficient estimate, the relationship between human capital and tourism receipts proved to be positive and statistically significant. Human capital development positively affects tourism receipts in this country group.
\end{abstract}

Keywords: Tourism Receipts, Human Capital, Panel Data Analysis.

Received: 14.01 .2020

Accepted: 05.04.2020

Suggested Citation:

Alancioğlu, E. and Şit, M. (2020). The Role of Human Capital Development in Tourism: A Panel Data Analysis for Tourism-Dependent Economies, Journal of Turkish Tourism Research, 4(2): 11091122.

(C) 2020 Türk Turizm Araştırmaları Dergisi. 


\section{Gíriş}

Ekonomisi önemli ölçüde turizm gelirlerine bağlı olan ülkelerde hükümetler ve politika yapıcılar ekonomik büyüme ve rekabet gücünü en üst düzeye çıkarmak için turizm endüstrisine öncelik vermektedir. 2015 Dünya Ekonomik Forumu'nun raporuna göre, bu devletler turizm endüstrisini ekonomik büyüme ve kalkınma arayışlarında diğer büyük ülkelerden daha fazla önemsemektedir. Turizm sektörü bu ekonomilerin politika yapıcıları için öncelikli ilgi alanı olmuştur. Çünkü bu ekonomilerde turizm gelirlerinin Gayrisafi Yurt İçi Hasıla (GSYH) içindeki payı oldukça yüksektir. Sürdürülebilirliğin sağlanması amacıyla projelerin geliştirilmesi, aktörlerin koordine edilmesi, sektörün tanıtımı ve geliştirilmesine yönelik gerekli kaynakların sağlanması amacıyla kamu fonlarındaki büyük paylar turizme sektörüne kanalize edilmektedir. Bu sektörün devletten aldığı büyük destekle turizm sektörü hem bireysel hem de özel yatırımcılar için cazip hale gelmektedir (Fahimi vd., 2018:62).

Günümüzde kalkınmada turizm sektörünün ön planda olduğu ekonomilerdełurizm gelirlerinin artırılması ve ekonomik kalkınmanın hızlandırılmasında hükümetler, özel kurumlar ve bireyler beşeri sermayenin önemini kabul etmektedirler. Bu bağlamda turizme bağlı ekonomilerin beşeri sermaye gelişimine yönelik ortak çabaları güçlendirmesi gerekmektedir. Özellikle gelişmekte olan ülkelerde sektörlerin uluslararası rekabet gücünün artırılmasında beşeri sermayenin geliştirilmesi kabul gören bir politika tavsiyesidir. Bu çalışmada, turizme bağlı ülkelerde beşeri sermaye turizm ilişkisinin geçerliliği ampirik olarak analiz edilmiştir. Bu amaçla GSYH'si içerisinde turizm gelirleri yüksek olan 10 gelişmekte olan ülkenin (Kıbrıs, Hırvatistan, Dominik Cumhuriyeti, Jamaika, İzlanda, Malta, Fas, Filipinler, Panama ve Tayland) verileri kullanılmıştır.

Çalışmada öncelikle kuramsal çerçevede beşeri sermaye ve turizm ilişkisi açıklanmıştır. Sonrasında konu ile ilgili literatür araştırması sunulmuştur. Hipotezi test eden ampirik analiz yöntemi ve veriler açıklanarak; analiz bulguları paylaşılmıştır. Sonuç bölümünde ise; bulgular ışığında genel değerlendirme ve politika önerileri sunulmuştur.

\section{BEŞERI SERMAYE-TURIZM İLIŞKİSI}

Ekonomik İşbirliği ve Kalkınma Örgütü (OECD) tarafından beşeri sermayenin tanımı “bireylerin kişisel, sosyal ve ekonomik refahın yaratılmasını kolaylaştıran bilgi, beceri, yetkinlik ve nitelikler" olarak adlandırılmaktadır (OECD, 2001: 18). Schultz'a (1993) göre ise, "beşeri sermaye" terimi, firma varlıklarını ve çalışanlarını iyileştirmek için anahtar bir unsur olarak tanımlanmıştır. Bu bağlamda beşeri sermaye hem üretkenliği arttırır hem de rekabet avantajını korur.

Beşeri sermaye teorisi, makro ekonomide kalkınma teorisinin temel unsurları arasındadır (Schultz, 1993). Becker (1993) "İnsan Sermayesi" adlı kitabında eğitime özel atıfta bulunarak beşeri sermayeye dikkat çekmiştir. Becker (1993), okullaşma, bilgisayar eğitimi kursu, tıbbi bakım harcamaları gibi farklı sermaye türleri olduğunu savunmaktadır. Klasik iktisatçılar emeği sermaye veya üretim malı gibi değerlendirmişlerdir. Bu çerçevede emek, kara yol açıyorsa değerlidir. Bununla birlikte, emek terimi ile geleneksel olarak ilişkilendirilen anlamının aksine, beşeri sermaye, eğitim ve öğretim yoluyla biriken bilgi, uzmanlık ve beceriyi ifade eder. Beşeri sermaye teorisinin sosyal ve ekonomik önemini vurgulayan Becker (1993), tüm sermayenin en değerli olanının insana yapılan yatırım olduğunu belirtmiştir. Uygulamadan bağımsız olarak 
Becker (1993), eğitim ve öğretimi beşeri sermayeye yapılan en önemli yatırım olarak görmektedir (Marimuthu vd., 2009:266)

Beşeri sermaye gelişimi, bir ülkenin sosyo-ekonomik gelişimi için paha biçilmez bir varlık olan ekonomik büyüme ve kalkınmanın önemli gereksinimlerden biridir (Ibok, 2014). Ejeteh-Iroh'un (2010), herhangi bir kuruluşun en önemli değerinin insan sermayesi olduğunu savunur. Çünkü kuruluşun politikaları ve programları yalnızca onlar tarafından entegre edilir ve dile getirilir. Bu nedenle beşeri sermaye kaynağı, turizm endüstrisi de dahil olmak üzere tüm kuruluşların başarısı için gereklidir. Canina vd. (2006), turizm endüstrisinde beşeri sermayenin hizmet odaklı çalışanlar, güçlendirilmiş çalışanlar ve bağlı çalışanlardan oluştuğunu ve bu endüstrideki beşeri sermayeye yapılan yatırımların doğrudan kuruluşların genel performansı ile ilişkili olduğunu belirtmektedir. Esu (2012), turizmde bir destinasyonun rekabet üstünlügüünü geliştirme yeteneğinin, insan sermayesi tabanının seviyesi ve kalitesinin bir işlevi olduğunu ileri sürmektedir. Turizm endüstrisi, diğer birçok endüstrinin aksine emek yoğundur. Paydaşların beşeri sermayenin önemini takdir etmeleri ve gelişimlerine kaynak yatırmaları genellikle zordur. Turizmde güzel yapılar inşa etmek, en iyi ekipmanı satın almak ve marka reklamcılığına yatırım yapmak için ne kadar harcanırsa harcansın, hepsi doğru insanlar olmadan boşa çıkar (Olusegun vd., 2016: 195).

\section{LITERATÜR ARAŞTIRMASI}

Tecle vd. (2006), gelirleri büyük ölçüde turizme dayalı olan Seyşel Adaları, Namibya, Zambiya, Lesoto, Madagaskar gibi Afrika ülkelerinde beşeri sermaye gelişiminin turizme etkisini araştırmıştır. Yazarlara göre bölgenin avantajlarına rağmen Afrika'nın küresel turizm pazarındaki payı düşüktür. Bunun sebebi genellikle düşük hizmet standartları ve sektörde uygun vasıflı işgücü sıkıntısı bulunmasıdır. Beşeri sermaye gelişimi herhangi bir destinasyonun turizm ürününün önemli bir bileşenini oluşturduğundan, insan kaynakları geliştirme yoluyla turizmin ekonomik katkısını arttırılabilir.

Mehregan vd., (2012), turizmi temsilen turist sayısı ile beşeri sermaye bileşenleri olarak gelir, eğitim ve doğumda yaşam beklentisi değişkenleri ile İran ekonomisi için ilişkiyi incelemiştir. ARDL yönteminin uygulandığ çalışmada, 1967-2007 dönemi verileri kullanılmıştır. Sonuçlar kısa ve uzun vadede yabancı turist girişi ile insani gelişme endeksi arasında pozitif ve anlamlı bir ilişki olduğunu göstermektedir. Ayrıca gelir endeksi, yaşam beklentisi endeksi ve eğitim endeksi de dahil olmak üzere beşeri sermaye bileşenlerinin, yabancı turistlerin uzun vadede gelişlerini önemli ölçüde etkilemektedir. Croes (2012), ise çalışmasında bu çalışmaya benzer biçimde reel turizm geliri ile beşeri sermaye endeksi arasındaki ilişkiyi araştırmıştır. Kosta Rika ve Nikaragua özelinde yapılan çalışmada 1990-2009 dönemi verileri üzerinden ekonometrik yöntem olarak Granger Nedensellik testi uygulanmıştır. Araştırma sonucunda; Nikaragua'da turizm ve beşeri sermaye karşılıklı nedensellik ilişkisi tespit edilmiştir. Söz konusu ilişki Kosta Rika' da turizmden beşeri sermayeye doğru tek yönlüdür. Yazara göre; turizm gelirlerinin artmasının önemi, faydalarının dağılımına ve turizm gelirlerinin beşeri sermayeyi (halk sağlığı, eğitim, güvenlik vb.) desteklemek için tahsis edilmesine bağlıdır. 
Esu (2012), çalışmasında, beşeri sermaye yönetimi ile turizmin gelişmesi arasındaki bağlantıyı gösteren kavramsal bir çerçeve sunmuştur. Esu'ya göre bir turizm destinasyonundaki hizmet sunumunun kalitesi, beşeri sermayenin kalitesinin bir yansımasıdır. Yazar Nijerya'daki turizm gelişimini olumlu yönde etkileyebilmek için beşeri sermaye gelişiminin önemli olduğunu ve kaliteli insan sermayesi üretecek bir yaklaşımı önermektedir.

Croes ve Rivera (2015), turizm ve beşeri sermaye arasındaki bağlantıyı araştırmış ve turizm ile beşeri sermaye arasında çift yönlü ilişki olduğunu iddia etmiştir. Çalışmada iki yapı arasındaki bağlantıyı değerlendirmek için eşbütünleşme ve Granger nedensellik analizlerini kullanılmıştır. Sonuçlar turizm ve beşeri sermaye gelişimi arasındaki uzun vadeli ilişkiyi göstermektedir ve her iki değişken de pozitif işarete sahiptir.

Rivera (2017), çalışmasında gelen turist sayısı ve beşeri sermaye endeksi değişkenlerini kullanarak, Engle-Granger eşbütünleşme, ECM ve Granger Nedensellik testleri uygulamıştır. Bu çalışmada, Ekvador'daki insani kalkınma, ekonomik büyüme ve turizm arasındaki dinamik ilişkiyi değerlendirmek için hata düzeltme modeli kullanılmıştır. Çalışmadan elde edilen sonuçlar, değişkenler arasında uzun vadeli ilişkinin varlığını göstermektedir. Ampirik sonuçlara göre; turizm insani gelişmeyi desteklemez iken beşeri sermaye turizmi etkilemektedir.

Biagi vd. (2017), beşeri sermaye ve turizm ilişkisini turizm ve beşeri sermaye endeksi değişkenlerini ele alarak panel regresyon yöntemi ile araştırmıştır. Çalışmada, 1996-2008 yılları arasında 63 ülke seçimi için ilişkiyi analiz edilmiştir. Bulgular, turizm ile beşeri sermaye gelişimi arasında pozitif bir ilişki olduğunu doğrulamaktadır. Bu sonuç, ev sahibi ülkedeki turizmin etkisinin ekonomik etki açısından çok daha geniş olduğunu göstermektedir. Ayrıca, insani gelişme ile turizm arasındaki ilişkinin daha fazla araştııılması gerektiğini ortaya koymaktadır.

Adedipe ve Adelike (2016), Nijerya turizm endüstrisindeki beşeri sermaye gelişiminin yapısını çalkantılı fakat büyüyen bir ekonominin zemininde incelemeyi amaçlamaktadır. Çalışma, Nijerya turizm endüstrisinin karşılaştığı başlıca zorlukları gözden geçirmektedir. Turizm sektörünün istihdama katkısının da incelendiği çalışmanın bulguları Nijerya'da turizm endüstrisinde beşeri sermayenin geliştirilmesi ve iyileştirilmesi için özel sektörün, hükümetin ve diğer paydaşların girdisinin gerekli olduğunu göstermektedir.

Stauvermann ve Kumar (2017), çalışmasında beşeri sermaye yatırımlarının turizm sektörüne olan etkisini incelemiştir. Çalışmada basitleştirilmiş bir OLG (Overlapping Generations) yaklaşımı geliştirilmiştir. İşgücü verimliliğindeki artışın, yalnızca turizm talebinin esnek olması durumunda olumlu büyüme etkileri oluşturduğu sonucuna varmıştır.

Folarin vd. (2017), 1998'den 2014'e kadar olan dönemi kapsayan yirmi beş (25) Afrika ülkesinden oluşan bir panel veri kullanarak turizmin beşeri sermaye gelişimini etkilemedeki rolünü araştırłmıştır. GMM (System General Moment Method) tahmin tekniği ile yapılan çalışma bulguları, turist sayısı ve turizm gelirlerinin Afrika'daki beşeri sermaye gelişimi üzerinde olumlu ve anlamlı bir etkiye sahip olduğunu göstermiştir. Yine GMM tahmin tekniği ile yapılan başka bir çalışmada Kostakis ve Theodoropoulou (2017), turizm ve beşeri sermaye gelişiminin büyüme üzerindeki etkisini incelemiştir. 2000-2014 döneminde Güney Avrupa bölgeleri bu çalışmanın örnek olayı olmuştur. Bu çalışmada kullanılan GMM yaklaşımı, bölgesel ekonomik durumun belirleyicilerinin varlığını test ederken mekansal bağımlılık gibi faktörleri de hesaba katar. 
Ampirik bulgular turizm ve beşeri sermaye gelişimi arasında ilişki olduğunu ve her iki değişkenin bölgesel geliri olumlu etkilediğini göstermektedir.

Fahimi vd., (2018), 1995-2015 dönemi için Barbados, Küba, Kıbrıs, Dominik Cumhuriyeti, Fiji, Haiti, İzlanda, Malta, Mauritius ve Trinidad ve Tobago ekonomilerinde beşeri sermaye gelişimi ve turizm ilişkisini araştırmıştır. Çalışmada kesitsel bağımlılı̆̆ı açıklayan ikinci nesil panel yaklaşımını kullanılmıştır. Turizm, beşeri sermaye ve ekonomik büyüme arasındaki nedensellik ilişkisi ve etkileşim, Dumitrescu ve Hurlin tarafından geliştirilen Granger nedensellik testi yaklaşımı kullanılarak incelenmiştir. Ampirik sonuçlar turizme bağlı büyümeyi, turizme bağlı beşeri sermaye gelişimini ve beşeri sermaye gelişimine bağlı büyümeyi destekleyen kantlar sunmaktadır.

Akyol ve Karakuş (2018), aksi yönde turizm gelirlerinin beşeri sermayenin gelişimine etkisini ele almıştır. Bu amaç doğrultusunda gelişmekte olan ülke sepetinden seçilmiş on iki ülkeye ait veriler 2002 -2015 dönemi için sabit etkili Driscoll-Kraay ve Panel Kantil modeller ile analiz edilmiştir. Araştırma bulgularına göre gelişmekte olan ülkelerde turizm gelirlerinde yaşanan artışlar beşeri sermaye düzeyini arttırmaktadır. Buna göre bu ülkelerin turizm gelirlerinin artması bireylerin iktisadi gelişimlerini desteklemektedir.

Hajiyeva ve Teymurova (2019), Azerbaycan ekonomisinde turizm ve beşeri sermaye arasındaki ilişkiyi ölçmek için korelasyon- regresyon yöntemini tercih etmiştir. 2005-2017 dönemi verileri üzerinden basit regresyon analizi yapılan çalışmada bağımlı değişken olarak turizm gelirleri ele alınırken bağımsız değişkenler yükseköğretim mezun sayısı, turist sayısı, kişi başına gelir ve yaşam beklentisidir. Çalışmanın bulgularına göre; beşeri sermaye ve turizm arasında anlamlı ilişki tespit edilmiştir. Buna göre; yükseköğretim kurumlarının mezunlarının sayısında ki \% 1 artış turizm gelirlerini ortalama olarak 0,01 milyon manat arttıracaktır. Ayrıca turizm hizmetlerinin kalitesi, personelin kişisel ve mesleki niteliklerine bağlıdır. Sonuç olarak, turizm kurumlarının stratejik hedeflerine ulaşmak ve rekabetçi turizm önerileri hazırlamak için beşeri sermayenin geliştirilmesine sürdürülebilir yatırımlar yapılması gerektiğine dikkat çekilmiştir. Farklı bir araştırmada ise Denizci ve Taşcı (2010) beşeri sermaye gelişiminin turizmde markalaşma değeri üzerinde ki etkisini incelemiştir. Hem nitel hem de nicel önlemleri entegre etmek için yapısal eşitlik modellemesi (SEM) kullanılmıştır. Çalışma sonucunda beşeri sermayenin bir parçası olarak, beşeri sermaye değerlemesi- yani çalışan tazminatı - kuruluşun marka değeri üzerinde önemli bir etkiye sahip olduğu belirtilmiştir.

Türkiye ekonomisi için yapılan çalışmalar incelendiğinde Tandoğan (2017), turizm ve beşeri sermaye gelişimi arasındaki nedensellik ilişkisini, 1970-2013 dönemi için Toda ve Yamamoto nedensellik sınaması yardımıyla araştırmıştır. Elde edilen bulgular neticesinde, beşeri sermaye gelişiminden turizme doğru tek yönlü bir nedensellik ilişkisinin varlığı tespit edilmiştir.

Göçer ve Aydın (2016), turizmi temsilen turizm gelirleri ile doktor sayısı ve sağlık harcamaları arasındaki ilişkiyi Maki Çoklu Yapısal Kırılmalı Eş Bütünleşme ve Toda-Yamamoto Nedensellik testleri ile analiz etmiştir. 1975-2013 yılı verilerinin uygulandığ çalışma sonucunda; turizm gelirleri ve doktor sayısı arasında çift yönlü, sağlık harcamalarından turizm gelirlerine doğru ise tek yönlü bir nedensellik ilişkisi bulunmuştur. Uzun dönemde doktor sayısındaki ve sağlık harcamalarındaki \%1'lik artışların turizm gelirini sırasıyla \%2.2 ve \%0.54 oranında arttırdığ 1 görülmüştür. 
Sonuç olarak, beşeri sermaye gelişimi/bileşenleri ile turizm sektörü (gelir/turist sayısı) arasındaki pozitif ilişki açıkça görülmektedir. Bunun yanında iki değişken arasında nedensellik ilişkisinin de ampirik olarak kanıtlandığı çalışmalar çoğunluktadır. Genel olarak literatüre bakıldığında turizm ve beşeri sermaye ilişkisini araştırılmasında turizmi temsilen ya turizm gelirleri ya da turist sayısının değişken olarak belirlendiği görülmüştür. Bunun yanında beşeri sermayeyi temsilen de genellikle beşeri sermaye indeksi analize dahil edilmiştir. Bu çalışmada da literatüre uygun olarak turizm geliri ve beşeri sermaye indeksi değişkenleri üzerinden hipotez test edilecektir. Çalışmanın literatüre katkısı iki yönlüdür. Bu katkılar; özellikle ekonomisi turizme bağlı ülkeler için yapılması ve ikinci kuşak modellerle testler yapılarak ülke bazlı katsayı tahmin sonuçları elde edilmesidir.

\section{MATERYAL VE YÖNTEM}

Bu çalışmada örneklem ülke grubunun beşeri sermayeyi temsilen beşeri sermaye endeksi (HCI) ve turizmi temsilen turizm gelirleri (TR) (1000 Amerikan doları) kullanılmıştır. Bu değişkenler ile ilgili veriler Dünya Bankası ve PWT 9.1 (Penn World Table) veri tabanından alınmıştır. Turizm gelirleri değişkeni logaritmik formda analize dahil edilmiştir. Çalışmada analize dahil edilen ülkeler seçilirken her kıtadan ülke alınmıştır.

Çalışmada test edilen hipoteze ilişkin ekonometrik model aşağıdaki gibidir:

$$
\ln T R_{i t}=\alpha_{0}+\beta_{1} H C I+\mu_{i t}
$$

Modelde hangi eşbütünleşme testlerinin (birinci ve ikinci kuşak) uygulanacağını tercih etmek için serilerin yatay kesit bağımlılığı tespit edilmelidir. Çalışmada seriler arasında kurulan modelde yatay kesit bağımlılık sorunu bulunup bulunmadığı Pesaran (2015) CD testi ile sınanmıştır. Bunun yanında kurulan modelin homojenliği Swamy $S$ testi ile incelenmiştir.

Durağan olmayan serileri ile kurulan modeller sahte regresyon problemine yol açabilmektedir. Bu bakımdan araştırma için uygun tahmincileri belirlemeden önce serilerin durağanlık düzeyleri tespit edilmelidir. Panel birim kök testleri birinci ve ikinci kuşak testler olmak üzere iki gruba ayrılmaktadır. Birinci kuşak birim kök testleri yatay kesit bağımlılık olmadığını varsaymakta, ikinci kuşak birim kök testleri ise seriler arasında yatay kesit bağımlılığa izin vermektedir (Tatoğlu, 2017: 21).

Yatay kesit bağımlılı̆̆ı belirlenen serilerin durağanlıkları ikinci kuşak panel birim kök testlerinden Hadri- Kurozumi (2012) testi ile incelenmiştir. Araştırmada değişkenler arasındaki eşbütünleşme ilişkisi ikinci kuşak panel eşbütünleşme testlerinden Gengenbach vd., (2016) testi ile tahmin edilmiştir. Bu testin en önemli özelliği heterojenlik, dengesiz paneller ve birimlerde eşit olmayan gecikme uzunluklarına izin vermesidir (Tatoğlu, 2017:207). Eşbütünleşme ilişkisinin saptanmasından sonra değişkenlerin uzun dönem katsayılarının tahmin edilmesi gerekir. Araştırmada değişkenler arasındaki eşbütünleşme ilişkisine ait uzun dönem katsayıları birimler arası korelasyona izin veren ve heterojenliği göz önünde bulunduran ikinci kuşak heterojen Pedroni (2001) ortalama grup dinamik en küçük kareler (DOLSMG) tahmincisi ile analiz edilmiştir. 


\section{BULGULAR VE TARTIŞMA}

Bu çalışmada beşeri sermaye ile turizm gelirleri ilişkisini test etmek için öncellikle modelin yatay kesit bağımlılığı ve homojenlik testleri yapılmıştır. İlk olarak panelin yatay kesit bağımlılığı Pesaran (2015) CD testiyle belirlenmiştir. Tablo 1'de ki bulgulara göre, panelin geneli için yatay kesit bağımlılık tespit edilmiştir.

Tablo 1. Yatay Kesit Bağımlılık Test Bulguları

\begin{tabular}{|l|l|l|}
\hline \multirow{2}{*}{ Değişkenler } & \multicolumn{2}{|c|}{ Test } \\
\hline \multirow{2}{*}{$\operatorname{lnTR}$} & \multicolumn{2}{|c|}{ Pesaran (2015) CD-test: } \\
\cline { 2 - 4 } & 9.665 P-val \\
\hline HCI & 9.936 & $(0.000)$ \\
\hline
\end{tabular}

Modelin homojenliğinin belirlenmesi ise Swamy S testi ile belirlenmiştir. Tablo 2' de ki bulgulara göre, olasılık değeri "chi2" değerinden büyük olduğu için $\mathrm{H}_{0}$ hipotezi reddedilmekte ve modelin heterojen olduğunu göstermektedir. Bu durumda eşbütünleşme testlerinden heterojen olanların sonuçlarına güvenmek ve heterojen paneller için önerilen tahmin yöntemleri kullanmak uygun olmaktadır. Testler sonucunda ikinci nesil panel veri analizinin yapılmasının uygun olduğuna karar verilmiştir.

Tablo 2. Swamy S homojenlik Testi Sonuçları

\begin{tabular}{|c|c|c|c|c|c|c|}
\hline LnTR & Coef. & Std. Err. & $\mathrm{z}$ & $P>|z|$ & 95\% Conf. & Interval \\
\hline HCI & 1.5907 & .6528001 & 2.44 & 0.015 & 3121074 & 2.8707 \\
\hline _cons & -3.4007 & 1.398607 & -2.45 & 0.014 & -6.12507 & -0.681061 \\
\hline \multicolumn{5}{|c|}{ Test of parameterconstancy: } & \multicolumn{2}{|c|}{ Prob $>$ chi $2=0.0000$} \\
\hline
\end{tabular}

Tablo 3'te ise; Hadri-Kurozumi birim kök testi sonuçları sunulmuştur. Optimal gecikme uzunlukları, Schwarz bilgi kriterine göre belirlenerek 4 (max.) olarak alınmıştır. Tablo 3'e göre değişkenler düzeyde birim kök içerirken birinci farkları alındığında durağan hale gelmektedirler. Birim kök testi bulguları eşbütünleşme testinin güvenilirliğini kanıtlayan sonuçlar vermiştir. 
Tablo 3. Hadri-Kurozumi Birim Kök Testi Sonuçları

\begin{tabular}{|c|c|c|}
\hline \multirow[b]{2}{*}{ Düzey } & \multicolumn{2}{|c|}{ Sabit ve Trend } \\
\hline & T-İst & P- Değeri \\
\hline \multicolumn{3}{|l|}{$\ln T R$} \\
\hline ZA_spac & 2.0032 & [ 0.0226 ] \\
\hline ZA_la & 1.6094 & [ 0.0538 ] \\
\hline \multicolumn{3}{|l|}{ HCI } \\
\hline ZA_spac & 2.3318 & [ 0.0099 ] \\
\hline ZA_la & 8.4377 & [ 0.0000 ] \\
\hline \multicolumn{3}{|l|}{ Birinci Farkı } \\
\hline \multicolumn{3}{|l|}{$\operatorname{lnTR}$} \\
\hline ZA_spac & 8.0611 & {$[0.0000$ ] } \\
\hline ZA_la & 7.9455 & [ 0.0000 ] \\
\hline \multicolumn{3}{|l|}{ HCI } \\
\hline ZA_spac & 2.3847 & [ 0.0085 ] \\
\hline ZA_la & 3.7345 & {$[0.0001]$} \\
\hline
\end{tabular}

Çalışmada değişkenler arasındaki uzun dönem ilişki, yatay kesit bağımlığı ve heterojenliği dikkatte alan ikinci kuşak Gengenbach vd., (2016) panel eşbütünleşme testi ile sınanmıştır. Tablo $4^{\prime}$ te test bulguları gösterilmektedir. Bulgulara göre, beşeri sermaye ile turizm gelirleri arasında uzun dönemli bir ilişki tespit edilmiştir.

Tablo 4. Gengenbach vd. 2016 Eşbütünleşme Testi ve Pedroni (2001) DOLSMG Tahminleri

\begin{tabular}{|l|c|c|}
\hline \multicolumn{2}{|c|}{ Hci } \\
\hline TR bağımlı değişkendir. & & \\
\hline & T- bar değeri & Prob değeri \\
\hline ECT-1 & $\mathbf{- 2 . 6 9 5}$ & $<=0.1$ \\
\hline & Hci & t-istatistik \\
\hline Model & Beta & $33.36^{* * *}$ \\
\hline Kıbris & 3.822 & $4.289^{* * *}$ \\
\hline Hırvatistan & .8891 & -.1429 \\
\hline Dominik Cumhuriyeti & -.2679 & $9.019^{* * *}$ \\
\hline İzlanda & 1.744 & $5.122^{* * *}$ \\
\hline Jamaika & 3.145 & $2.024^{* *}$ \\
\hline Malta & 6.731 & $7.469^{* * *}$ \\
\hline Fas & 1.772 & $5.553^{* * *}$ \\
\hline Panama & 3.73 & $28.27^{* * *}$ \\
\hline Filipinler & 10.38 & $8.701^{* * *}$ \\
\hline Tayland & 6.507 & $35.18^{* * *}$ \\
\hline
\end{tabular}

Not: ${ }^{* * *},{ }^{* *},{ }^{*}$ sirasıyla $\% 1, \% 5, \% 10$ anlamlılık düzeylerini belirtir. 
Modelin panel eşbütünleşme hata düzeltme parametresinin (ECT-1)'in anlamlılığ incelendiğinde T- bar değerleri ve olasılık oranları \%95 güvenirlik düzeyinde anlamlı çıkmıştır. $\mathrm{Bu}$ durumda beşeri sermaye ve turizm gelirleri arasında uzun dönemde bir ilişki olduğu kanitlanmıştır.

Serilerin uzun dönem katsayıları yatay kesit bağımlılı̆̆ı ve heterojenliği dikkatte alan Pedroni (2001) DOLSMG katsayı tahmincisi ile test edilmiştir. Tablo 4'te beşeri sermaye ve turizm gelirleri değişkenleri arasında uzun dönemli ilişkinin DOLSMG ile tahmin sonuçları görülmektedir. Tablo 4 'te ki verilere göre, uzun dönem parametresinin $t$ istatistiği anlamlıdır. DOLSMG sonuçlarına göre beşeri sermaye uzun dönemde turizm gelirlerini etkilemektedir. Beşeri sermayedeki \%1'lik artış turizm gelirlerini \%3.822 artırmaktadır. Tabloda ayrıca ülke bazlı DOLSMG uzun dönem katsayı tahmin sonuçları gösterilmektedir.

Ülkeler bazında sonuçlar beşeri sermayede yaşana artış incelendiğinde, Kıbrıs, Dominik Cumhuriyeti, İzlanda, Jamaika, Malta, Fas, Panama, Filipinler, Tayland'da turizm gelirleri üzerinde olumlu yönde bir etkiye sahip olduğu tespit edilmiştir. Buna karşı Hırvatistan'da anlamlı bir ilişki gözlemlenememiştir. Tahmin edilen modele ilişkin uzun dönem parametrelerinin birimlere göre grafikleri Şekil 1'de gösterilmiştir.

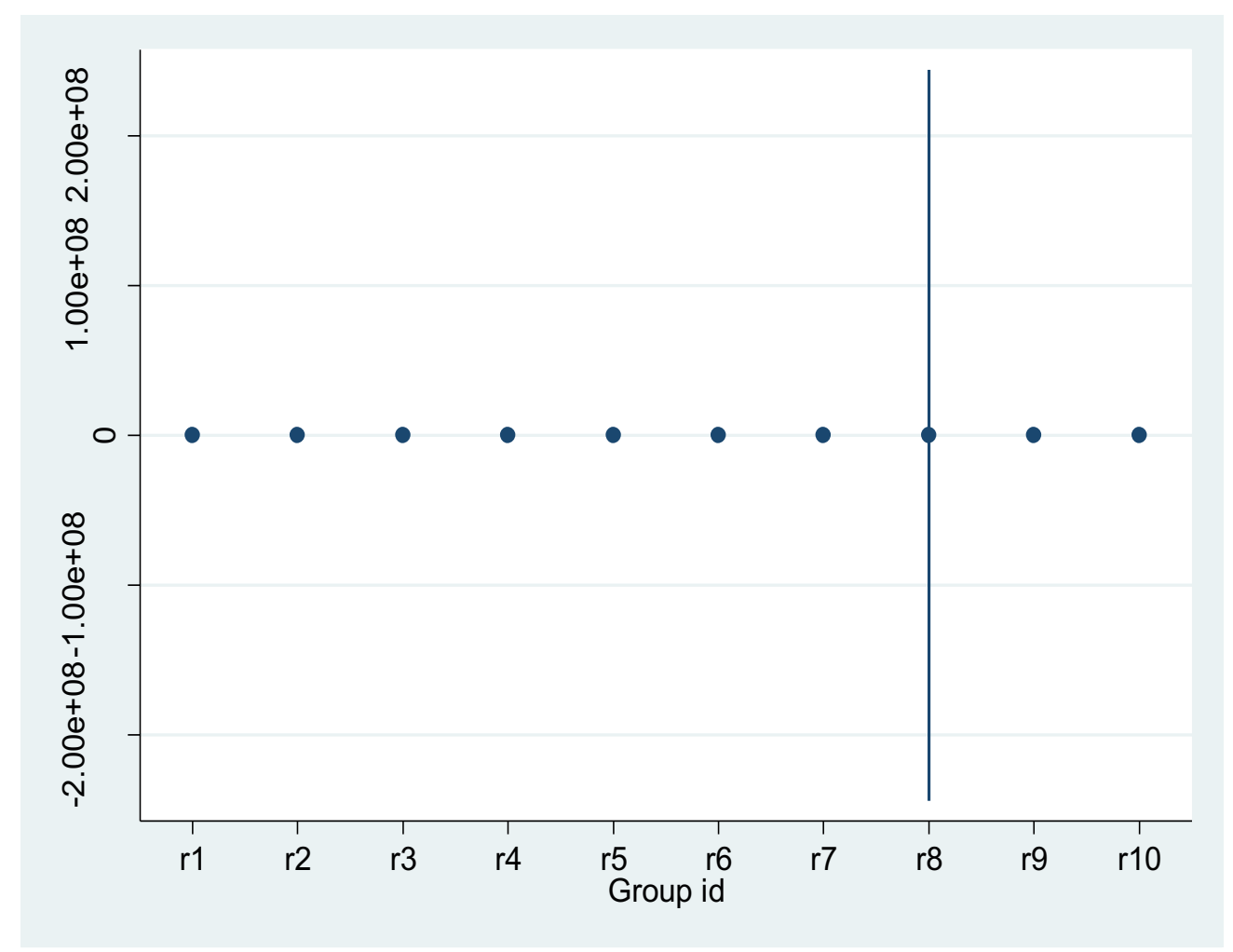

Şekil 1. Modele İlişkin ECT(-1)'in Birimlere Göre Grafiği 


\section{SONUÇ VE ÖNERILLER}

Günümüzde bilgiye olan ihtiyaç ve güvendeki artış beşeri sermaye faktörlerinin değerini büyük ölçüde artırmaktadır. Bilgi toplumunda teknolojik gelişmelerle beraber özellikle sanayi, finans vb. alanlarda insan emeğine bağımlılık azalsa da aksine turizm endüstrisinde emek yoğunluğu devam etmektedir. Turizmin bu özelliği sektör için beşeri sermaye gelişiminin önemini daha da arttırmaktadır. Bu çalışmada beşeri sermaye endeksinin turizm gelirlerine olan etkisi araştırılmıştır. Çalışmanın ampirik analiz kısmında öncelikle yatay kesit bağımlılık ve homojenlik birim kök testleri yapılmıştır. Testler sonucunda ikinci nesil panel veri analizinin yapılmasının uygun olduğuna karar verilmiştir.

Hadri-Kurozumi birim kök testine göre tüm değişkenlerin birinci farklarında I(1) durağan olduğu tespit edilmiştir. Birim kök testi bulguları eşbütünleşme testinin güvenilirliğini kanıtlayan sonuçlar vermiştir. Değişkenler arasındaki uzun dönemli ilişkiyi analiz etmek için Gengenbach vd. (2016) eşbütünleşme testi yapılmıştır. Bulgulara göre, beşeri sermaye ile turizm gelirleri arasında uzun dönemli bir ilişki tespit edilmiştir. Ayrıca iki değişken arasındaki ilişkinin yönünü tespit etmek için DOLSMG tahmincisi ile analiz yapılmıştır. Tahminci sonuçlarına göre; panelin genelinde pozitif (3.822) ve anlamlı bir ilişki tespit edilmiştir. Buna göre; ülke grubu için beşeri sermaye gelişimindeki \%1'lik artış 3,82'lik bir artışa yol açacaktır. Bunun yanında bu test ülke bazlı katsayı tahmin sonuçları da vermektedir. Ülke bazlı sonuçlar incelendiğinde Hırvatistan hariç tüm ülkelerde beşeri sermaye gelişiminin turizm gelirleri üzerinde pozitif etkisi görülmektedir. Özellikle GSYH'si içerisinde turizm gelirleri payının daha yüksek olduğu İzlanda, Jamaika, Panama ve Filipinler gibi ekonomilerde beşeri sermayenin katsayısı (3,14-6,7310,38 ve 6,50 ) yüksek ve ortalamanın üstündedir. İzlanda dışında diğer ülkelerin genelinin gelişmekte olan ekonomi konumunda olması bu ülkelerde beşeri sermayenin de gelişim içinde olduğunu gösterir. Bu durumda turizm gelirlerinin arttırılarak ekonomilerinin büyümesinde beşeri sermayenin önemini arttırmaktadır. Ayrıca gelişmekte olan bu ülkelerde beşeri sermaye artışı turizm destinasyonlarında eksik olan hizmet kalitesinin yükselmesine ve sonucunda turizm talebinin artışına sebep olacaktır. Bulgular literatürdeki çalışmalarla [Croes (2012), Croes ve Rivera (2015), Rivera (2017), Fahimi vd. (2018), Hajiyeva ve Teymurova (2019), Tandoğan (2017)] benzerlik göstermektedir. Beklenenin aksine katsayı Hırvatistan'da negatif çıkmıştır. Zaten bu bulgu istatistiki olarak anlamlı değildir.

Beşeri sermayeye yatırımlarının, herhangi bir ülkenin bilgi teknolojisinden yararlanabilmesinde gerekli olduğu yadsınamaz bir gerçektir. Eğitim ve öğretim programları en etkili beşeri sermaye stratejileri olarak görüldüğünden ekonomisi büyük oranda turizme bağlı olan bu ülkelerde temel ve mesleki eğitim programlarının bilgi teknolojilerine göre yeniden düzenlenmesi kişisel performansı artırarak turizmde yüksek yatırım getirisi sağlayabilir. Eğitim ve öğretim programlarında turizm müfredatı oluşturulmalıdır. Mezunların belirli beceri ve niteliklerle donatılarak kalitesinin arttırılması, çalışanların profesyonel olarak iş görmelerini sağlayacaktır. Çünkü mesleki eğitim, sunulan hizmet kalitesinde, bir endüstriyi rakiplerinden ayıran en önemli özelliklerden biridir. Bu durum emek yoğun bir sektör olan turizm sektöründe kritik bir rol oynamaktadır. Ayrıca etkin beşeri sermaye yatırımlarının sonucunda, çalışanlar veya 
vatandaşlar turizm disiplini özelliklerine sahip olabilecektir. Bu ülkelerde hem özel hem de kamu kesimi turizm sektöründe rekabetçi bir insan sermayesi oluşturmak için yurtdışındaki eğitim kurumlarıyla işbirliği yapabilir. Bunun yanında; beşeri sermayenin bir diğer göstergesi olan sağlık alanında da yatırımlar arttırılmalıdır. Bu durum özellikle yurtdışı turizm talebini arttırmada ülkeyi ziyaret etmek isteyen yabancların kendini güvende hissetmesi adına önem taşımaktadır.

Ayrıca; turizm sektöründeki aktörler yüksek maliyet sebebiyle beşeri sermayeye yatırım yapmakta çekingen olabilirler. Dolayısıyla özel sektörün beşeri sermaye yatırımları yapması için elverişli ortam sağlanması gerekir. Bu yüzden emek piyasasındaki problemleri çözmek için kamu sektörü tarafından yapılan harcamalar arttırılmalıdır. Bunun sonucunda turizm firmaları beşeri sermayenin yatırım getirisini fark edebilir. Bu durum, eğitim ve öğretim yoluyla beşeri sermaye yatırımları için kaynak harcama konusunda firmaları harekete geçirebilir. Bu olgu özellikle istikrarsız ekonomiye sahip gelişmekte olan ülkelerdeki kuruluşlar için önemlidir.

Sonuç olarak, analiz edilen ülkelerin coğrafi özellikleri farklı olsa da beşeri sermaye turizm gelirlerinin önemli bir belirleyicisi olarak tespit edilmiştir. Bu sonuç, ekonomik büyüme ve kalkınma için uygulanacak politikaların belirlenmesinde bu ülke grubu için yol gösterici olacaktır.

\section{KAYNAKÇA}

Adedipe, C. O., and Adeleke, B. O. (2016). Human capital development in the Nigerian hospitality industry. Worldwide Hospitality and Tourism Themes 8(2), 195-206.

Akyol H. ve Karakuş K. (2018). Turizm Beşeri Sermayenin Belirleyicisi midir? Sabit Etkili Driscoll-Kraay ve Panel Kantil Yaklaşımlar, IV. Uluslararası Mesleki ve Teknik Bilimler Kongresi, Erzurum.

Becker, G.S. (1993). Human Capital: A Theoretical and Empirical Analysis with Special Reference to Education (3 $r d$ ed.). Chicago: University of Chicago Press.

Biagi, B., Ladu, M. G., and Royuela, V. (2017). Human development and tourism specialization. Evidence from a panel of developed and developing countries. International Journal of Tourism Research, 19(2), 160-178.

Canina, L., Enz, C.A. and Walsh, K. (2006). Intellectual capital: a key driver of hotel performance [Electronic article], Cornell Hospitality Reports, 6(10), 6-12.

Croes, R. (2012). Assessing Tourism Development from Sen's Capability Approach, Journal of Travel Research, 51(5), 542-554.

Croes, R., and Rivera, M. (2015). Tourism and Human Development. Revista Latino-Americana de Turismologia, 1(2), 17-29. 
Denizci, B., and Tasci, A. D. (2010). Modeling the commonly-assumed relationship between human capital and brand equity in tourism. Journal of Hospitality Marketing $\&$ Management, 19(6), 610-628.

Ejeteh-Iroh, C.J. (2010). The Impact of Training and Development Policy on Job Satisfaction, College Publishers, Pankshin.

Esu, B.B. (2012). Linking human capital management with tourism development and management for economic survival: the Nigerian experience, International Journal of Business and Social Sciences, 3(11), 276-287.

Fahimi, A., Saint Akadiri, S., Seraj, M., and Akadiri, A. C. (2018). Testing the role of tourism and human capital development in economic growth. A panel causality study of micro states. Tourism Management Perspectives, 28, 62-70.

Folarin, O., Oladipupo, E., Ajogbeje, K., and Adeniyi, O. (2017). Does tourism development contribute to human capital development in Africa? Turizam: Medunarodni Znanstveno-Stručni Časopis, 65(3), 314-329.

Gengenbach, C., Urbain J.P. and Westerlund J. (2016). Error Correction Testing in Panels with Common Stochastic Trends, Journal of Applied Econometrics, 31(6), 982-1004.

Göçer, İ., ve Aydin, N. (2016). Türkiye'de Sağlık Değişkenlerinin Turizm Gelirine Etkisi: Çoklu Yapısal Kırılmalı Bir Analiz. Çankırı Karatekin Üniversitesi İktisadi ve İdari Bilimler Fakültesi Dergisi, 6(1), 777-800.

Hadri, K. and Kurozumi E. (2012). A Simple Panel Stationarity Test in the Presence of Serial Correlation and a Common Factor, Economics Letter, 115, 31-34.

Hajiyeva, L., and Teymurova, V. (2019). Analysis of The Impact of The Human Capital on Tourism Development in Azerbaijan, Economic and Social Development: Book of Proceedings, 15791588.

Ibok, E.E. (2014), The impact of human capital development and economic empowerment of Akwa-Ibom State, Nigeria, Global Journal of Human Resource Management, 2(3), 37-44.

Kostakis, I., and Theodoropoulou, E. (2017). Spatial analysis of the nexus between tourismhuman capital-economic growth: Evidence for the period 2000-2014 among NUTS II Southern European regions. Tourism Economics, 23(7), 1523-1534.

Mehregan, N., Kordbacheh, H., and Akbari, A. (2012). Foreign tourism and human development in Iran. International Proceedings of Economics Development \& Research, 50(4), 15-18.

Marimuthu, M., Arokiasamy, L., and Ismail, M. (2009). Human capital development and its impact on firm performance: Evidence from developmental economics. Journal of international social research, 2(8), 265-272.

Organization for Economic Co-operation and Development (OECD) (2001). The Well- Being of Nations: The Role of Human and Social Capital. Paris: OECD. 
Olusegun Adedipe, C. and Olusola Adeleke, B. (2016). Human capital development in the Nigerian hospitality industry: The imperative for a stakeholder driven initiative, Worldwide Hospitality and Tourism Themes, 8(2), 195-206.

Penn World Table (PWT), (2020). PWT 9.1 Datas https://www.rug.nl/ggdc/productivity/pwt/, [Erişim tarihi: 10.02.2020].

Peseran M.H., (2015). Testing Weak Cross-Sectional Dependence in Large Panels, Econometric Reviews, 34, 1089-1117.

Rivera, M. A. (2017). The synergies between human development, economic growth, and tourism within a developing country: An empirical model for Ecuador. Journal of destination marketing $\mathcal{E}$ management, 6(3), 221-232.

Schultz, T.W. (1993). The economic importance of human capital in modernization, Education Economics, 1(1), 13-19.

Stauvermann, P. J., and Kumar, R. R. (2017). Productivity growth and income in the tourism sector: Role of tourism demand and human capital investment, Tourism Management, 61, 426-433.

Tandoğan, D. (2017). Türkiye'de Turizm ve Beşeri Sermaye Gelişimi İlişkisi: 1970-2013 Nedensellik Yaklaşımı, Uluslararası Ekonomik Araştırmalar Dergisi, 3(4), 525-534.

Tatoğlu, F. Y. (2017). Panel Zaman Serileri Analizi. İstanbul: Beta Basım Yayın Dağıtım.

Tecle, Y. H., and Schroenn, J. L. (2006). The contribution of HRD to tourism-led development in an African context: economics, South African Journal of Economic and Management Sciences, 9(4), 444-457.

Worldbank. (2020). PWT 9.1 Datas. https://data.worldbank.org/indicator (12.02.2020).

World Travel and Tourism Council (2015). Travel and tourism economic impact: European Union. London, UK: World Travel and Tourism Council. 